\title{
eCOti
DiAno
}

Revista Mídia e Cotidiano

ISSN: 2178-602X

Artigo Seção Temática

Volume 14, Número 1, jan-abr de 2020

Submetido em: 06/11/2019

Aprovado em: 31/01/2020

\section{Criança cidadã?: os manuais de redação e as orientações sobre infância e adolescência $^{1}$}

\section{The Citizen child?: manuals of style and usage and the guidance on childhood and adolescence}

\author{
Thaís FURTADO \\ Juliana DORETTO ${ }^{3}$
}

\begin{abstract}
Resumo
Tendo como base as legislações que envolvem a cobertura das questões da infância e da adolescência pela imprensa, este artigo objetiva verificar se os manuais de redação dos jornais de maior tiragem no Brasil trazem orientações para seus colaboradores - e divulgadas também ao público - sobre a abordagem de temas que envolvem as crianças. Levando em conta que vários autores consideram que uma das finalidades do jornalismo é prezar pela cidadania, busca-se perceber se essas orientações incluem tanto o direito das crianças de serem protegidas quanto o de participarem da vida em sociedade. Conclui-se que os manuais de $O$ Globo, Folha de S. Paulo e Zero Hora tratam meninos e meninas como seres submetidos à guarda da lei, mas isso ocorre pelo receio em descumprir a legislação, e não pela preocupação com a criança como cidadã.
\end{abstract}

Palavras-chave: Infância. Cidadania. ECA. Jornalismo. Manuais de redação.

\begin{abstract}
Based on the laws that involve the coverage of childhood and adolescence issues by the press, this article aims to verify if the manuals of style and usage of the largest circulation newspapers in Brazil provide guidelines for their collaborators - also released to the public — about the approaches that they should adopt for addressing topics involving children. Considering that several authors state that one of the purposes of journalism is to foster citizenship, we seek to understand whether these guidelines, when they do exist, include both children's right to be protected and children's right to participate in life in society. We concluded that the manuals of $O$ Globo, Folha de $S$.

\footnotetext{
1 A primeira versão deste trabalho foi apresentada no $16^{\circ}$ Encontro Nacional de Pesquisadores em Jornalismo, ocorrido no Fiam-Faam Centro Universitário, em novembro de 2018. Comunicação pela mesma universidade. E-mail: thaisfurtado93@gmail.com. ORCID: 0000-0001-94741800.

3 Jornalista. Professora do Programa de Pós-Graduação em Linguagens, Mídia e Arte da Pontifícia Universidade Católica de Campinas. Doutora em Ciências da Comunicação pela Universidade Nova de Lisboa, em Portugal. E-mail: jdoretto@gmail.com. ORCID: 0000-0002-1860-3622.
}

2 Jornalista. Professora da Universidade Federal do Rio Grande do Sul (UFRGS). Doutora em Ciências da
\end{abstract}


Paulo and Zero Hora treat boys and girls as individuals that are subjected to law enforcement. However, this results from a fear of their breaking the law, rather than from a concern with children as citizens.

Keywords: Childhood. Citizenship. Child and Adolescent Statute. Journalism. Manuals of style and usage.

\section{Introdução}

Uma das finalidades do jornalismo é oferecer ao público informações de qualidade e necessárias ao exercício e à construção dos direitos e deveres dos cidadãos (REGINATO, 2016; LAGO, 2014; PREVEDELLO, 2008). Para Lago (2014, p. 176), “[...] no corolário de valores e representações do campo jornalístico da atualidade está a sua responsabilidade social, que o liga a conceitos como interesse público, democracia e cidadania". Prevedello (2008, p. 45), por sua vez, define cidadania como "um conjunto de direitos civis, políticos e sociais, capazes de garantir ao indivíduo o exercício da liberdade, desde que com responsabilidades, deveres e respeitos aos direitos alheios".

Para que a imprensa realmente contribua para a formação da cidadania, é necessário que ela dê espaço à multiplicidade de opiniões e vozes. "Se o jornalismo mostra sempre as mesmas pautas, parece que o mundo é sempre do mesmo jeito. Trazer a complexidade do mundo ajuda na formação da cidadania e na formação de uma opinião pública crítica, esclarecida e atuante" (REGINATO, 2016, p. 229). Neste artigo tentamos entender como o jornalismo se relaciona com as questões que envolvem a cidadania de um grupo muitas vezes esquecido pelos jornalistas: o das crianças e adolescentes.

Essa preocupação tem sido explicitada de forma recorrente em nossas pesquisas conjuntas, que se dedicam às análises de representações de crianças e adolescentes na mídia brasileira (FURTADO; DORETTO, 2019; DORETTO; FURTADO, 2018, 2019) — com especial atenção ao jornalismo. Nosso objetivo tem sido o de buscar compreender como os discursos midiáticos constroem a imagem de crianças e adolescentes neles representados, de acordo com diferentes contextos socioeconômicos, tendo em vista a defesa dos mais jovens como sujeitos de direito - ou seja, que podem exercer sua cidadania da forma mais plena possível. Nossas mais recentes conclusões têm atestado muitas vezes a representação estereotipada das crianças e adolescentes, que vem atrelada 


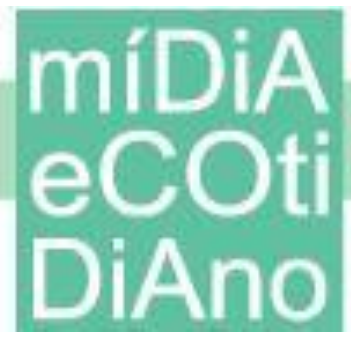

à pouca escuta desses jovens pelos jornalistas brasileiros, ainda que saibamos dos constrangimentos e dificuldades enfrentadas pelos repórteres para fazê-lo e que tenhamos identificado avanços. Podemos resumir essa nossa trajetória em uma de nossas reflexões mais recentes, em que destacamos a problemática:

[...] as crianças são tradicionalmente representadas no jornalismo não por meio de suas próprias falas, mas pelos discursos de seus pais e tutores ou de representantes de órgãos que falam sobre elas, como escolas e organizações de saúde. Essa forma de representação faz com que a criança não apareça como cidadã plena, que participa da vida social (a não ser como consumidora), mas como uma imagem dicotômica: ou é indivíduo ingênuo e puro, a ser protegido (no caso das crianças de classes mais altas), ou então um sujeito sob a responsabilidade do Estado, porque cometeu crimes (e assim teria perdido até mesmo sua condição idealizada de infante atrelada à inocência), ou porque está em situação de vulnerabilidade (com a sua condição de "ser criança" posta em risco) (FURTADO; DORETTO, 2019, p. 158).

Assim, acompanhamos proposições de outros pesquisadores que se interessam pelo tema. Ponte (2005), por exemplo, ao estudar a construção da infância pelo discurso jornalístico, com olhar atento a Portugal, afirma que as crianças formam um dos grupos mais silenciados socialmente (e o jornalismo reflete essa prática), embora carreguem grande carga simbólica. Isso ocorre por elas serem consideradas pelos adultos como seres inocentes e desprotegidos - o que lhes confere um caráter idílico, em relação aos vícios da idade adulta —, produzindo representações muitas vezes estereotipadas. "Num jornalismo onde a personalização é valor-notícia, as crianças são por excelência 'boas vítimas' ou preocupantes 'traidores' da sua própria condição quando não correspondem a essa imagem de fragilidade" (PONTE, 2005, p. 143).

Buckingham (2000) é uma referência nessa discussão ao alertar para o fato de que as crianças, atualmente, têm status e autoridade como consumidoras, mas nem sempre são reconhecidas pela sociedade como cidadãs. Normalmente, elas são excluídas das decisões políticas que influenciam suas vidas por serem vistas pelos adultos como incapazes de opinar sobre essas decisões e delas participar. É evidente que existem diferenças em relação às possibilidades de atuação social de uma criança muito pequena e de um adolescente. Entretanto, considerar todos eles como incapazes de fazer parte de 


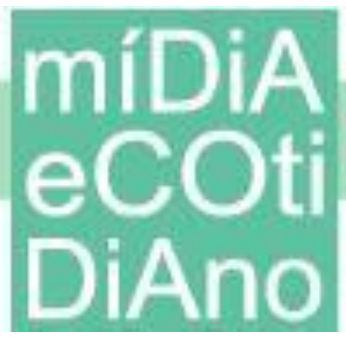

deliberações sociais leva a uma reflexão circular: será que elas não são julgadas como incompetentes justamente por serem excluídas desse processo, ficando assim impossibilitadas de mostrar suas capacidades? Acreditamos, assim, que o jornalismo, por ter entre suas finalidades a formação da cidadania, deveria estimular essa participação, e não reproduzir os padrões sociais.

Por esse motivo, decidimos examinar os manuais de redação dos principais jornais brasileiros (considerados os mais relevantes para a prática noticiosa, como veremos a seguir), para entender como tratam da cobertura da infância e adolescência. Em primeiro lugar, o fazemos porque compreendemos que, embora os manuais não sejam definidores absolutos da forma como os jornalistas irão trabalhar, estudar o modo como o jornalismo define as regras para a construção de seu discurso é também uma maneira de entender como ele se comunica com a sociedade. Nesse sentido, Albuquerque e Holzbach (2008), ao estudar diferentes versões do Manual da Folha de S. Paulo, dizem que essa publicação é uma forma de construir um discurso sobre o contrato representativo proposto pelos jornais a seus leitores, em relação aos poderes do Estado, representado pela lei. Apesar de ser uma pesquisa sobre as diretrizes de apenas um jornal, acreditamos que a reflexão dos autores revela uma articulação interessante, que ressalta a importância dos manuais para a promoção da cidadania pelo jornalismo:

Dizer que os manuais elaboram uma versão particular do contrato representativo significa que eles se propõem de alguma forma a atuar como mediadores entre os cidadãos e o Estado. Na verdade, eles não se referem diretamente a nenhum dos dois, mas o fazem por vias indiretas. No caso dos cidadãos, o seu papel é ocupado pelos leitores [...]. Quanto às instituições políticas, os manuais raramente se referem a elas explicitamente; via de regra eles relacionam a Folha a elas pela referência às leis (ALBUQUERQUE; HOLZBACH, 2008, p. 159).

Além disso, acompanhamos Buckingham (2000, p. 245, grifo do autor) quando ele propõe que a discussão não deve envolver a proteção das crianças aos "males que as mídias poderão infligir a elas, mas, ao contrário, como as mídias poderiam preparar as crianças mais efetivamente para as responsabilidades da cidadania adulta - ou mesmo habilitá-las a intervir nas decisões políticas que governam sua vida". Para isso, em primeiro lugar, é preciso conhecer a legislação brasileira sobre os direitos das crianças e 
adolescentes, com especial atenção à mídia, tendo em vista que é esse o fundamento institucional mais explícito para o exercício de sua cidadania.

\section{O marco legal da infância e da adolescência}

No Brasil, a principal legislação sobre os direitos da infância e adolescência é o ECA, Estatuto da Criança e do Adolescente (Lei no 8.069, de 13 de julho de 1990). A publicação Estatuto da Criança e do Adolescente: um guia para jornalistas (2011), da $\mathrm{Andi}^{4}$, diz que a lei surgiu a partir de uma grande mobilização social e que o estatuto "é tido como um marco para os direitos da criança e do adolescente no Brasil, substituindo o Código de Menores, de 1979. Traz em sua base a doutrina de proteção integral e reforça o princípio da criança e do adolescente como "prioridade absoluta"” (REDE ANDI BRASIL, 2011, p. 14). O trabalho ainda explica que, enquanto o Código de Menores visava apenas ações de proteção e vigilância de crianças e jovens autores de atos infracionais, o ECA se volta a todos os que têm menos de 18 anos, compreendendo que eles são sujeitos de direito, ou seja, que devem participar da vida social, para além de serem alvos de proteção.

Dos artigos do ECA, chamam a atenção dois deles, que estão relacionados ao trabalho da imprensa. No título "Do acesso à Justiça", no Artigo 143, é dito que está "vedada a divulgação de atos judiciais, policiais e administrativos que digam respeito a crianças e adolescentes a que se atribua autoria de ato infracional" e que "qualquer notícia a respeito do fato não poderá identificar a criança ou adolescente, vedando-se fotografia, referência a nome, apelido, filiação, parentesco, residência e, inclusive, iniciais do nome e sobrenome.” (BRASIL, 1990b). Já o Artigo 247 enquadra como infração “divulgar, total ou parcialmente, sem autorização devida, por qualquer meio de comunicação, nome, ato ou documento de procedimento policial, administrativo ou judicial relativo a criança ou adolescente a que se atribua ato infracional” (BRASIL, 1990b), prevendo pena (multa) para quem não respeitar essa legislação. O Parágrafo $1^{\circ}$ do mesmo artigo diz que também

\footnotetext{
${ }^{4}$ A Rede de Notícias de Direitos da Infância é uma organização não governamental voltada à promoção dos direitos humanos, que surgiu com foco na proteção das crianças e adolescentes e na cobertura dessas questões pela imprensa. Importante ressaltar que o guia citado tem a função de explicar aos jornalistas sobre os direitos das crianças e dos adolescentes, mas também acaba por incentivar pouco a escuta de jovens em pautas cotidianas.
} 


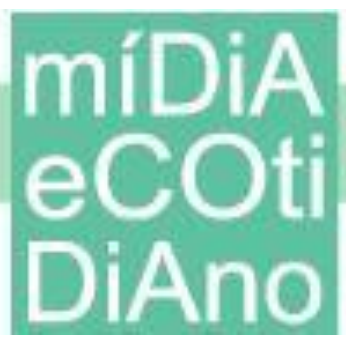

está prevista multa para "quem exibe, total ou parcialmente, fotografia de criança ou adolescente envolvido em ato infracional, ou qualquer ilustração que lhe diga respeito ou se refira a atos que lhe sejam atribuídos, de forma a permitir sua identificação, direta ou indiretamente" (BRASIL, 1990b).

A elaboração do ECA foi inspirada em legislação anterior, de 1989: a Convenção sobre os Direitos da Criança, capitaneada pela Organização das Nações Unidas e ratificada pelo Brasil em setembro de 1990, ou seja, poucos meses após a promulgação do estatuto. Rosemberg e Mariano (2010) mostram que "dois meses antes de sancionar o ECA [...] o então Presidente Fernando Collor de Mello anunciava [...] a criação do Ministério da Criança, concomitantemente ao encaminhamento, ao Congresso Nacional, da proposta de ratificação da Convenção". As autoras dizem também que a maior inovação desse acordo internacional foi estender às crianças todas as prerrogativas de cidadania estabelecidas na Declaração dos Direitos Humanos (1948), ao mesmo tempo em que foi preservado o ideário presente na Declaração dos Direitos da Criança (1959), que destacava a proteção da criança: “apela a que os pais, os homens e as mulheres em sua qualidade de indivíduos, e as organizações voluntárias, as autoridades locais e os Governos nacionais reconheçam estes direitos e se empenhem pela sua observância"5.

Rosemberg e Mariano (2010) afirmam ainda que, por conta dessa confluência entre direitos de proteção, provisão e participação, a Convenção gera debates sobre sua aplicabilidade, no sentido de haver variadas situações em que essas prerrogativas possam se tornar conflituosas. Assim, determinados direitos à proteção podem ser questionados justamente pela existência de outros, da ordem da participação, o que pode gerar omissões adultas em casos estruturados pelas relações intergeracionais (e, portanto, de poder). Ou seja, situações em que adultos se retiram de suas posições dominantes, apenas como efeito discursivo, em nome de uma liberdade infantil que nunca é plena, pois o mundo social é construído a partir das decisões dos adultos.

[...] cabe-nos indagar se reconhecer as crianças como atores sociais dotadas de competências para apreender e alterar a realidade, com algum (ou certo) grau de consciência sobre o que pensam, sentem e desejam, com capacidade para emitir opiniões e fazer escolhas -

\footnotetext{
${ }^{5}$ Disponível em: <http://www.direitoshumanos.usp.br/index.php/Crian\%C3\%A7a/declaracao-dos-direitos-
} da-crianca.html>. Acesso em: 9 set. 2019. 
significa, também, reconhecer que devem assumir o ônus de decisões importantes ou de ser envolvidas em processos judiciais, cujo controle lhes escapa, em boa medida, porque as instituições estão erigidas e funcionam em sociedades adultocêntricas? (ROSEMBERG; MARIANO, 2010, p. 721).

Essas questões, por estarem na base da construção da Convenção, se estendem, portanto, para o Estatuto da Criança e do Adolescente, que, como vimos, ao mesmo tempo em que diz que "a criança e o adolescente gozam de todos os direitos fundamentais inerentes à pessoa humana" (Art. $3^{\circ}$ ), também "reconhece a condição peculiar de desenvolvimento, o que faz os direitos se aplicarem a crianças, adolescentes e adultos de forma diferenciada" (Art. $\left.6^{\circ}\right)$.

A Convenção também traz diretrizes que envolvem o tratamento da infância e da adolescência pelos meios de comunicação. Destacamos aqui o Artigo 13 - "A criança terá direito à liberdade de expressão. Esse direito incluirá a liberdade de procurar, receber e divulgar informações e ideias de todo tipo, independentemente de fronteiras, de forma oral, escrita ou impressa" -, e o Artigo 17, ao dizer que:

Os Estados Partes reconhecem a função importante desempenhada pelos meios de comunicação e zelarão para que a criança tenha acesso a informações e materiais procedentes de diversas fontes nacionais e internacionais, especialmente informações e materiais que visem a promover seu bem-estar social, espiritual e moral e sua saúde (BRASIL, 1990a).

Esse ponto também é espelhado no ECA, quando, em seu Artigo 71, a legislação diz que "A criança e o adolescente têm direito a informação, cultura, lazer, esportes, diversões, espetáculos e produtos e serviços que respeitem sua condição peculiar de pessoa em desenvolvimento" (grifo nosso).

Tendo, então, debatido sobre as principais legislações que envolvem os direitos dos mais jovens (e a participação da mídia nesse processo), vamos nos voltar às diretrizes de trabalho que alguns dos principais jornais do país estabelecem a seus colaboradores para entender se esses veículos trazem orientações sobre a abordagem de temas que envolvem a cidadania das crianças - tanto pelo viés de sua proteção quanto pelo de sua participação na vida em sociedade. Para isso, olharemos para os manuais de redação que alguns desses periódicos elaboraram. 


\section{Os manuais de redação e a infância cidadã}

Vizeu (2008, p. 173) destaca que os manuais modernos surgiram, na imprensa brasileira, nas décadas de 1980 a 90, trazendo não apenas regras de uso da língua portuguesa e normas para a clareza do texto - como ocorriam com os manuais precursores, das primeiras décadas do século XX, nascidos nos jornais - mas igualmente "a postura das empresas jornalísticas com relação a determinados temas, que também deve ser assumida por seus jornalistas". Grillo (2003, p. 86) afirma que os manuais “expõem, ao mesmo tempo, as autorrepresentações e as instruções de regulamentação da prática jornalística”. Já Caprino (2002b, p. 101) resume as suas funções assim:

compilar e transmitir normas e padrões do estilo jornalístico [...] transmitir e divulgar a ideologia da empresa jornalística (ou política editorial) para jornalistas e leitores; divulgar o nome do jornal junto ao grande público, servindo de instrumento de marketing; estreitar sua relação com o leitor, estabelecendo uma espécie de contrato.

Ou seja, embora exista uma série de fatores políticos, culturais, econômicos, estruturais, hierárquicos, temporais, institucionais, éticos, entre outros, que determinam a prática jornalística, os manuais estabelecem explicitamente diretrizes sobre o comportamento do jornalista a serviço daquela publicação no seu trabalho de investigação dos fenômenos sociais a serem reportados em forma de texto noticioso. Sabemos ainda que nem sempre as orientações para a prática jornalística trazidas pelos manuais coincidem com o trabalho cotidiano dos jornalistas nas redações, já que a produção noticiosa "se altera em função das inter-relações entre as mudanças da sociedade" (GRILLO, 2003, p. 86), mas é inegável a força discursiva dessas publicações.

Isso ocorre porque, além de serem um compêndio de normas de gramática e de estilo, os manuais são um elemento importante da construção da identidade desses veículos na esfera social em que estão inscritos, servindo como instrumentos para divulgação do discurso autorrepresentativo daquele periódico: "fazem parte da prática jornalística e, com isso, integram a retórica do jornal, a qual se funda no conhecimento, na construção e na manutenção das expectativas do público leitor" (GRILLO, 2003, p. 86). Ou seja, os manuais são também um modo de os veículos dizerem como querem ser 


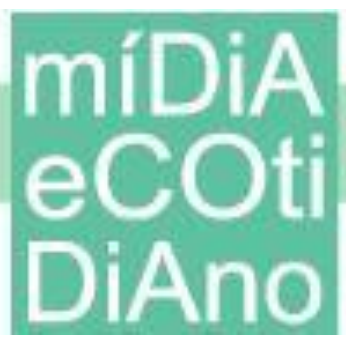

lidos (e aceitos) pela sociedade. Ainda que as práticas jornalísticas efetivas possam ampliar (ou reduzir) a potência das diretrizes ali retratadas, o registro formal de um discurso dos proprietários dos veículos sobre os seus produtos influencia o jornalista em seu trabalho, criando uma cultura redacional forte e que nem sempre consegue ser tensionada pelo reportariado, como exposto por Breed (1993, p. 231) no seu estudo clássico dos anos 50: “os padrões culturais da sala de redação produzem resultados insuficientes para as mais vastas necessidades democráticas. Qualquer mudança importante tendente a uma 'imprensa mais livre e responsável' deve provir de várias pressões sobre o publisher". É com esse olhar mais amplo sobre os manuais que eles serão aqui analisados.

Como primeiro delimitador para nossa análise, decidimos examinar apenas manuais de redação de jornais impressos. Embora existam publicações assim relativas a outros meios, concentramo-nos nesses que foram os primeiros a serem elaborados tanto no mundo quanto no Brasil e que acabaram se tornando referência em relação à construção das regras dos textos jornalísticos (MARQUES DE MELO, 2005; VIZEU, 2008). Caprino (2002a, p. 57), ao se referir aos manuais dos veículos diários impressos, afirma ainda que eles "ganharam, ao longo dos anos, status de livros que orientam a prática da redação fora da imprensa. Estão à venda nas livrarias e são consultados mesmo por aqueles que não têm nenhuma ligação com o jornalismo".

Dos cinco maiores jornais impressos brasileiros, de acordo com dados de tiragem impressa de 2017, quatro deles publicaram um manual de redação. Os que ocupam as posições de destaque são: Super Notícia (MG), com 156,5 mil exemplares por dia - o único sem manual -, seguido por $O$ Globo (RJ), cerca de 130,4 mil; Folha de S. Paulo, 121 mil; O Estado de S. Paulo, 114,5 mil; e Zero Hora (RS), 100,9 mil ${ }^{6}$. Consultamos a versão on-line do manual de $O$ Estado de $S$. Paulo $^{7}$ e percebemos que a obra não traz orientações sobre a cobertura do tema da infância e adolescência; por isso, ela não será analisada neste artigo, ainda que essa ausência já configure um importante dado sobre a

\footnotetext{
${ }^{6}$ Disponível em: <https://www.poder360.com.br/midia/tiragem-impressa-dos-maiores-jornais-perde-520mil-exemplares-em-3-anos/>. Acesso em: 9 jul. 2019.

${ }^{7}$ Disponível em: <https://www.estadao.com.br/manualredacao/>. Acesso em: 12 set. 2019.
} 


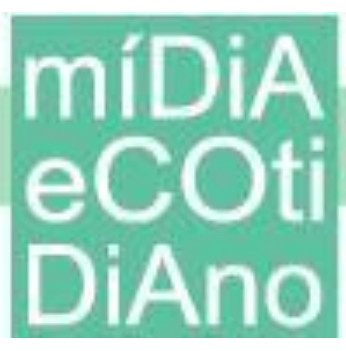

preocupação desse jornal com a temática em questão ${ }^{8}$. Os demais manuais trazem algumas considerações sobre o assunto. É sobre isso que falaremos a seguir.

Para elaborar a análise, realizamos consulta aos índices remissivos das publicações, em busca de termos que pudessem estar relacionados ao nosso objeto de investigação, como criança, menor, menor de idade e infância, além de leituras mais gerais, para que outros trechos pertinentes fossem encontrados. Posteriormente, apresentamos a forma como essa temática aparece em cada um desses trechos, relacionando-a com a legislação vigente sobre os direitos da infância e adolescência no Brasil e com reflexões teóricas sobre o assunto.

\section{Folha de S. Paulo}

O Manual da Redação da Folha de S. Paulo, de 1984, foi o primeiro, entre os analisados, a ser divulgado para o público. É também o que tem edição mais recente, lançada em fevereiro de 2018 - por isso, supõe-se que deveria tratar da cobertura da infância e adolescência de forma mais contemporânea.

Reportagem divulgada no site do jornal sobre o lançamento da obra, intitulada

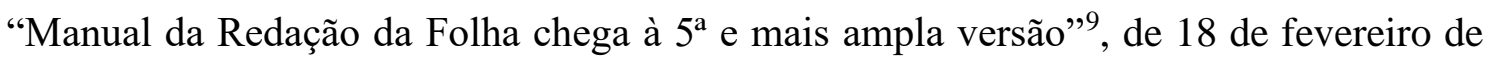
2018, diz que, "de acordo com Otavio Frias Filho, diretor de Redação, um manual geral, como o da Folha, vai muito além de apresentar orientações sobre o bom uso do português e de fixar a padronização a ser adotada pelos jornalistas da casa”. Segundo o texto, o livro tem a intenção de "dar alguma unidade às diferentes subculturas presentes na Redação (origens, estilos, faixas etárias diversas)" e "propicia uma régua comum pela qual se podem avaliar com mais objetividade desempenhos, erros, casos controvertidos etc." (grifos nossos).

\footnotetext{
${ }^{8} \mathrm{O}$ manual usa o termo criança(s), adolescente e menor como exemplos em várias construções textuais, mas, em relação a orientações (sessão "Esclareça as suas dúvidas"), aparece apenas a indicação de que se deve usar "você" ao entrevistar crianças (da mesma forma que se faz com artistas e esportistas); além disso, em "Os dez erros mais graves", surge: "Ele é 'de menor'. O de não existe: Ele é menor." Diz-se ainda que não se deve dizer que a criança tem "zero ano".

${ }^{9}$ Disponível em: <https://www1.folha.uol.com.br/poder/2018/02/manual-da-redacao-da-folha-chega-a-5ae-mais-ampla-versao.shtml>. Acesso em: 9 set. 2019.
} 
Na versão anterior, publicada pela primeira vez em 2001, o manual trazia informações sobre o tratamento dado a crianças e adolescentes sobretudo no verbete "Menor”, que aparece em duas seções. Uma delas é no "Anexo jurídico":

A legislação em vigor proíbe a identificação direta ou indireta de criança ou adolescentes a que se atribuam infrações. Na grafia de nomes, use as iniciais com ponto e sem espaço entre as letras. Evite apontar o nome dos pais e o endereço, já que isso pode acarretar a identificação indireta da pessoa. A Folha não publica foto que permita identificar criança ou adolescente infrator ou em situação de constrangimento. (FOLHA DE S. PAULO, 2001, p. 161, grifo do autor).

As mesmas informações aparecem em verbete de mesmo nome ("Menor"), mas na seção "Padronização e estilo": fala-se que o jornalista deve evitar o termo e proíbe-se publicação de "nome completo de criança e adolescente infrator" (recomendam-se iniciais, apesar de isso ser proibido pelo ECA) e de foto que "permita identificar ou expor a situação de constrangimento criança ou menor infrator" (FOLHA DE S. PAULO, 2001, p. 81). Na página 99, há outra pequena remissão ao termo adolescente, no verbete "teenager", sobre o significado do termo em português.

Na nova edição, o primeiro verbete que aborda o tema é "Imagens em redes sociais”, que está na parte 2 da obra, “Atuação jornalística” (que não aparecia com esse título na versão anterior), no capítulo "Prática":

É imprescindivel obter autorização dos pais ou responsáveis para reproduzir fotos ou vídeos em que crianças elou adolescentes sejam retratados. A regra se aplica mesmo que o menor de idade seja o autor da imagem e a tenha postado em seu perfil. Caso os pais ou responsáveis tenham postado foto da criança ou adolescente em rede social aberta, discuta eventual publicação com a Secretaria da Redação. (FOLHA DE S. PAULO, 2018, p. 102, grifos do autor).

No mesmo capítulo, surge o verbete "Menor de idade": "Crianças (Até os 12 anos incompletos) e adolescentes (dos 12 aos 18 anos) envolvidos em atos infracionais não podem ser identificados, mesmo com a autorização dos pais ou depois de terem atingido a maioridade (FOLHA DE S. PAULO, 2018, p. 106, grifos do autor). O texto ainda continua: 
Nesses casos, é igualmente vedado publicar iniciais do nome e do sobrenome, fotografia, referência a nome, apelido, filiação, parentesco ou residência. [...]

A Folha também não publica foto que permita identificar criança ou adolescente em situação de constrangimento, mesmo com o conhecimento e a autorização dos pais. A desobediência a essas determinações pode implicar a apreensão da publicação e a aplicação de multa, de acordo com a lei.

Os termos prender, deter e condenar não podem ser associados a pessoa com menos de 18 anos de idade a quem se atribua a prática de alguma infração. [...] No caso de crianças (até 12 anos incompletos), a lei (ECA, o Estatuto da Criança e do Adolescente) prescreve medidas como orientação e matrícula em estabelecimento de ensino, mas não privação de liberdade (FOLHA DE S. PAULO, 2018, p. 106, grifo do autor).

E, assim como ocorria na versão anterior do manual, outro verbete "Menor" aparece na seção ligada a regras de escrita (“Texto"), com remissão ao verbete "Menor" descrito acima. A orientação aqui é: "evite usar essa palavra genérica; prefira termos mais precisos, como criança e adolescente (FOLHA DE S. PAULO, 2018, p. 228, grifos do autor). Na página 224, na mesma seção, no verbete "Iniciais", aparece também a informação de que "crianças e adolescentes aos quais se atribuam atos infracionais não podem ser identificados nem pelas iniciais". No anexo "Três Poderes", no verbete "Prisão", surge o texto: "Criança e adolescente. Nunca use o termo prisão para menores de 18 anos. O correto é internação" (FOLHA DE S. PAULO, 2018, p. 412, grifos do autor). No mesmo anexo, há nova orientação, no verbete "Sequestro": Em caso de crianças retiradas de maternidade ou da guarda dos pais, use subtrair (termo técnico do Estatuto da Criança e do Adolescente) ou um sinônimo, mas não sequestrar (FOLHA DE S. PAULO, 2018, p. 416, grifos do autor). Por fim, o verbete "teen" se mantém, com breve alteração no nome, como se vê, mas redação parecida com a anterior.

Assim, notamos que, na obra da Folha, estão refletidos sobretudo os artigos do ECA que proíbem a divulgação de informações que possam identificar crianças e adolescentes em situação de vulnerabilidade - e cuja desobediência pode gerar multas -, com o avanço agora da proibição da escrita de iniciais do nome e sobrenome. É esse tipo de preocupação que resumia os verbetes "Menor", do manual anterior, mas que também está presente no atual "Menor de idade", de modo explícito, pois o texto fala de "aplicação de multa, de acordo com a lei". A migração do texto do anexo "Jurídico" para o capítulo 


\section{míDiA

"Prática" acentua ainda mais a ideia de incorporação da questão legal no dia a dia do trabalho. Outras atenções claras com a legislação aparecem ainda na citação do ECA em "Menor de idade" e "Prisão". Mas não há nenhuma orientação ao reportariado para ouvir a criança sempre que um assunto de seu interesse fosse abordado por uma pauta, o que contraria um dos seus princípios editoriais, expostos na página 13 do novo manual: "cultivar a pluralidade, seja ao divulgar um amplo espectro de opiniões, seja ao focalizar mais de um ângulo da notícia [...]".

Aliás, em relação ao acréscimo do termo "de idade" ao verbete "menor", vale observar aqui o possível reflexo de uma orientação dada à imprensa em campanha promovida pela organização Andi, já citada, que ressalta a mudança instaurada pelo ECA em relação ao anterior Código de Menores. Em glossário disponível no site da instituição ${ }^{10}$, a palavra menor vem acompanhada do seguinte texto: "Desde que o ECA entrou em vigor, é considerado inapropriado [...] Esse termo reproduz e endossa de forma subjetiva discriminações arraigadas e uma postura de exclusão social que remete ao extinto Código de Menores". Em outro link do site, na seção "Help desk", é dito que "o termo [...] se contrapõe ao paradigma dos direitos, ao identificar as crianças e adolescentes como indivíduos sob a tutela da família ou outros responsáveis e que, por isso, não gozam de seus direitos como cidadãos".

Chama a atenção, no entanto, que o próprio manual, em sua nova versão, usa o termo "menor de idade", no verbete sobre imagens em redes sociais ("A regra se aplica mesmo que o menor de idade [...]"). E isso já se repetia na edição anterior. Os lapsos são bastante curiosos por mostrarem como o texto que guia os procedimentos do jornal não adota diretrizes que ele mesmo estabelece e como a expressão parece ser ainda de uso corrente nas redações, apesar de o ECA abolir o termo. Assim, a ideia de criança como aquela que está em determinada faixa etária, ou seja, antes dos 18 anos, é o que rege a representação de infância para a Folha. Pensando o manual como um discurso autorrepresentativo, percebe-se aqui que o jornal não se atrela à figura de uma publicação

\footnotetext{
${ }^{10}$ Disponível em: <http://www.andi.org.br/glossario/menor />. Acesso em: 13 set. 2019.
} 


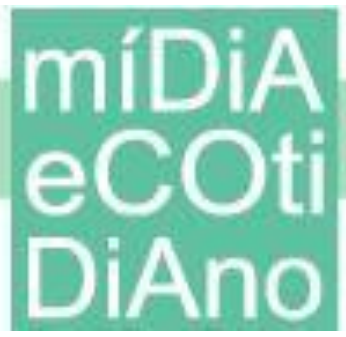

que valoriza as possibilidades de participação de meninos e meninas, mas os enquadram apenas como cidadãos alvos de proteção da lei.

Aliás, do ponto de vista da criança como sujeito de direitos, o novo verbete "imagens em redes sociais" é o que possibilita maior discussão. A Folha pede autorizações de pais ou responsáveis, mas não a anuência da própria criança, ainda que o ECA também diga, no Artigo 100, que "a promoção dos direitos e proteção da criança e do adolescente deve ser efetuada no respeito pela intimidade, direito à imagem e reserva da sua vida privada". Mesmo que o Estatuto estabeleça o dever dos pais e responsáveis em preservar a integridade da criança, cabe a ela também o direito à sua própria imagem. Aqui, é importante relembrar a tensão que pode por vezes existir entre os direitos de participação e proteção previstos no ECA e na Convenção. Nesse caso, o jornal favorece apenas o segundo deles. Em resumo, o manual, ainda que traga mais orientações sobre a cobertura da infância e adolescência que sua edição anterior, avança pouco em relação ao tratamento dos meninos e das meninas como cidadãos.

\section{O Globo}

O Manual de Redação e Estilo de O Globo foi publicado originalmente em 1992, editado pelo jornalista Luiz Garcia a partir de observações que ele fazia em relação a problemas estilísticos e de correção dos textos do jornal (CAPRINO, 2002a). Garcia optou por um formato diferente dos manuais de até então e o organizou em capítulos com texto corrido, e não somente em verbetes. A $28^{\text {a }}$ edição, publicada em 2001 e à qual tivemos acesso" ${ }^{11}$, manteve os títulos de capítulos, mas incluiu os apêndices "Em outros idiomas", "Expressões jurídicas" e "Termos de psicanálise e psiquiatria".

Assim como no manual da Folha, há algumas recomendações sobre a cobertura do tema da infância e adolescência. No capítulo "Estilo", está uma delas, no tópico em que são definidas as "Etapas da Vida".

Aquele que está para nascer é o nascituro (em algumas situações, o feto). Nas primeiras 24 horas, ele é recém-nascido. Até dois anos, a

\footnotetext{
${ }^{11} \mathrm{Em} 2005$ foi lançada a 30 a edição do Manual de Redação e Estilo de O Globo, sem modificações significativas para a temática deste artigo. Ver: <http://www.bocc.ubi.pt/pag/bocc-jornalismofrancisco.pdf >. Acesso em: 23 jan. 2020.
} 
criança pode ser chamada de bebê. Todos são meninos ou meninas até se transformarem em adolescentes, por volta dos 13 anos. Até a maioridade, serão também rapazes e moças - e jovens. Serão menores apenas quando as circunstâncias pedirem que se chame a atenção para a idade legal: diz-se, por exemplo, que um carro dirigido por um menor atropelou um adolescente (O GLOBO, 2001, p. 69, grifos do autor).

No apêndice "Palavras perigosas", também aparece o termo "Menor": "Palavra a ser substituída, sempre que possível, por outra mais específica: criança, menino, adolescente. Deve ter uso restrito às situações nas quais estiver em questão a idade legal da pessoa" (O GLOBO, 2001, p. 160, grifos do autor). Nos dois casos, existe preocupação semelhante à encontrada no manual da Folha sobre as recomendações dadas pela Andi, que aponta que o termo é pejorativo e excludente. Há também uma breve referência às crianças na página 38, no capítulo "Estilo", que indica que, ao se tratar de "gente muito moça, muito idosa ou morta no episódio" relatado, a idade é fundamental.

No capítulo sobre questões éticas, o tema é tratado a partir de outro viés, no tópico "Respeito à pessoa", mas utilizando o termo "menor".

O jornal respeita a exigência legal da não identificação do menor envolvido em delito ou situação humilhante. E respeita não apenas a letra da lei, mas o seu espírito; assim, não se limita a substituir nomes por iniciais, mas usa iniciais escolhidas aleatoriamente e omite outros dados que permitam identificação (como nome completo dos pais, endereço etc.). Evidentemente, também não se publicam fotos que mostrem claramente suas feições (O GLOBO, 2001, p. 115).

Nesse caso, quando cita a exigência legal, o manual se refere ao já abordado Artigo 143 do ECA, que proíbe identificação de criança ou adolescente infrator na imprensa. Chama a atenção o fato de o jornal dizer que respeita "não apenas a letra da lei, mas o seu espírito", como se, para proteger crianças e adolescentes, estivesse fazendo algo além do que a legislação já exige. Não há qualquer outra sugestão de atuação do reportariado de modo a compreender as variadas razões que levam uma criança a cometer um ato infracional, sem a busca de causas redutoras, o que seria esperado numa seção que se preocupa com questões éticas. Isso talvez pudesse ser considerado algo que respeitaria o "espírito" do ECA. De qualquer forma, também fica evidente a preocupação de $O$ Globo em não desobedecer a leis que possam provocar punição ao jornal. Esse cuidado também 


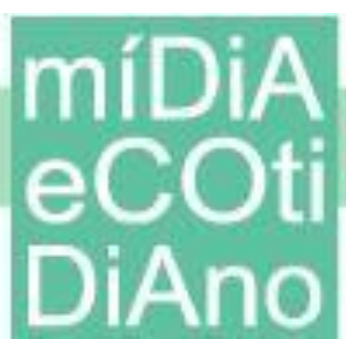

aparece no apêndice "Expressões jurídicas", no verbete "Curatela", que indica: "No caso dos menores de idade, o que existe é a tutela, exercida pelo tutor" (p. 215, grifos do autor).

O manual de $O$ Globo traz ainda pequenos textos que simulam redações jornalísticas para exemplificar o que se deve (ou não) escrever no jornal. Dois desses exemplos incluem crianças ou adolescentes. O primeiro está no capítulo "Estilo", ao tratar do lead de uma notícia. A recomendação é a de não usar detalhes que escondam a importância do fato principal:

Exemplo: "Dois meses depois de terem sido mantidos como reféns durante quase três horas por dois assaltantes que invadiram um prédio na avenida Paulo de Frontin, no Rio Comprido, os irmãos Antônio Marcos Quintans Novo, de 15 anos, e Thalita, de 13, continuam sitiados pelo medo." Bem menor e bem melhor: "Dois meses depois de serem mantidos como reféns por dois assaltantes durante quase três horas, dois irmãos de 15 e 13 anos continuam sitiados pelo medo" (O GLOBO, 2001, p. 32).

O outro exemplo está no apêndice "Acidentes de texto":

Fernanda, aos três anos, não sabia que uma das armadilhas da nossa língua é designar como "bala" não apenas as guloseimas que ela gostava de comer, como também o projétil que causou sua morte.

Exemplo de desastre estilístico produzido por tentativa mal concebida de enfeitar a narração. Parece que a menina morreu porque engoliu a bala (O GLOBO, 2001, p. 69, grifos do autor).

Os dois exemplos, assim como o já citado "Etapas da vida" (“[...] diz-se, por exemplo, que um carro dirigido por um menor atropelou um adolescente"), colocam as crianças em situações de fragilidade, ou relacionadas a atos infracionais, mesmo que o objetivo seja apenas dar exemplos de redação de um lead ou de uma frase ambígua. Isso reforça o que temos afirmado, em consonância com outros autores: meninos e meninas, nos discursos jornalísticos, vêm sendo representados normalmente a partir de estereótipos dicotômicos, o ser inocente, a ser protegido; e, em oposição, o delinquente, ainda que avanços tenham sido notados (FURTADO, DORETTO, 2019).

Por fim, vale dizer que no apêndice "Termos de psicanálise e psiquiatria", há também pontos que citam crianças, a maioria referindo-se a comportamentos patológicos ou relacionados a contravenções. São seis verbetes: 1) "Aberrações sexuais", aparece a 


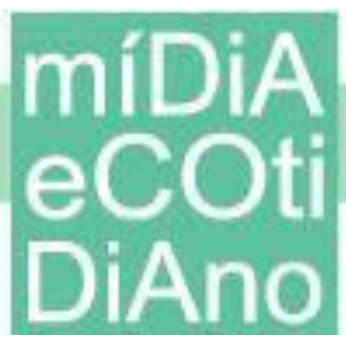

pedofilia como "relações sexuais com crianças"; 2) "Castração (complexo de)", explicase que, "No complexo de Édipo, a castração anatômica é temida pelas crianças como castigo pelos impulsos eróticos em relação aos pais" (o texto termina por dizer que "a saída do complexo edipiano é a entrada no complexo de castração: a criança 'castra' seus impulsos"”); 3 ) "Exibicionismo/exibicionista", o manual diz que é "Comum em crianças que estão descobrindo suas diferenças anatômicas"; 4) "Falo/fálico", afirma-se que "Dizemos que o bebê é o falo da mãe"; 5) "Perversismo ou perversidade/perversista", "Diz-se do adulto no qual persistem com exclusividade comportamentos sexuais perversos (pré-genitais), próprios da criança"; 6) "Regressão/regredido", há a explicação de que "A pessoa regredida (e não 'regressiva') comporta-se de maneira infantil [...]".

É possível questionar a razão de existir esse apêndice em um manual de redação de um jornal, tendo em vista a especificidade do assunto, mas também se pode ponderar que questões psicológicas se originam muitas vezes na infância e por isso existem tantas menções a crianças nessa parte do manual. Mesmo assim, chama a atenção que a maioria delas se refere a comportamentos vistos como problemáticos ou patológicos e até relacionados a contravenções.

\section{Zero Hora}

O jornal Zero Hora, de Porto Alegre, publicou suas primeiras diretrizes sobre a redação de seus textos em 1979, intituladas como Normas de Redação, com autoria do jornalista José Raimundo Manosso. O formato se aproxima de um livreto que, em sua introdução, explica que a ideia dessas normas surgiu no setor de Esportes, a quem se destinavam inicialmente, e que depois se expandiu para toda a redação. Diz também que foram baseadas em manuais de jornais do Rio de Janeiro e de São Paulo.

Nessa versão, só há uma referência às crianças, na página 14, em um tópico chamado "Recomendações", segundo o qual as pessoas, nos textos do jornal, "devem ser identificadas pelo nome completo na primeira vez que forem citadas no texto, pelo sobrenome daí por diante. Mas há muitas exceções a esta regra. Em geral, atletas, crianças, marginais, artistas são tratadas pelo primeiro nome ou apelido [...]”. É interessante perceber que as crianças, no final da década de 1970, estavam acompanhadas de outros grupos que podem ser considerados à margem da sociedade, ou que não 


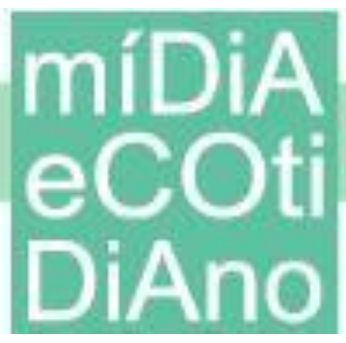

representam a maioria das fontes entrevistadas pelos jornalistas. Mesmo atletas e artistas, que, em muitos casos, acabam por ganhar notoriedade social, em sua maioria são profissionais que não se enquadram nos padrões ideais da sociedade. $\mathrm{O}$ uso do termo "marginais" para definir um grupo (hoje em desuso) chama a atenção. O acesso a regras jornalísticas do passado - não tão distante - possibilita a compreensão da origem de alguns hábitos difíceis de serem apagados das redações, como a forma de tratamento das fontes, o que, em certa medida, marca diferenças sociais.

Em 1994, Zero Hora publicou suas diretrizes atualizadas no Manual de Ética, Redação e Estilo, com apresentação do então diretor de redação, Augusto Nunes, que reforça a ideia de que os manuais acabam sendo referências também para o público externo: "Em tese, as regras se destinam a orientar o comportamento dos profissionais de ZH. Na prática, são úteis a qualquer brasileiro disposto a comunicar-se por meio de textos redigidos com correção e elegância" (ZERO HORA, 1994, p. 9).

O livro é dividido nos três temas que aparecem no título: "Ética", "Redação" e "Estilo", e se complementa com "Glossário", "Fontes de consulta" e "Índice remissivo". $\mathrm{Na}$ lista das principais "cartolas" (ou "chapéus") utilizadas por Zero Hora, aparece a palavra "Infância" (ZERO HORA, 1994, p. 29). No capítulo "Estilo", no tópico "Individualização", há um conselho: "A história sobre uma menina ferida numa guerra causa muito mais impacto que a divulgação do número de mortos na guerra" (ZERO HORA, 1994, p. 68). Semelhante ao manual de $O$ Globo, esse exemplo relaciona a criança - ou "uma menina" - a uma situação de sofrimento.

Mas é no tópico intitulado "Menores", dentro do capítulo "Ética", que a cobertura de questões da infância e da adolescência é tratada de forma explícita:

De acordo com o Estatuto da Criança e do Adolescente, nomes de menores envolvidos em crimes só podem ser identificados pelas iniciais e as fotos dos rostos devem exibir uma tarja. Em casos muito especiais, contudo, a omissão de nomes e imagens pode contribuir para que a sociedade se exima de sua responsabilidade sobre o problema, em prejuízo dos menores. Nesses casos, a decisão de publicar o nome completo e a foto do rosto de menor envolvido em ato ilícito só poderá ser tomada pelo diretor de Redação ou pelo editor-chefe (ZERO HORA, 1994, p. 18). 
É importante relembrar que o ECA indica que crianças e adolescentes a quem se atribua ato infracional não podem ser identificadas nem pelas iniciais do nome e sobrenome. O Estatuto também não indica que os rostos dessas crianças em fotos devem ser cobertos por uma tarja, e sim que imagens que as identifiquem estão vedadas. Portanto, mesmo que o manual tenha o cuidado de citar o ECA, o faz de forma equivocada. Mas o que chama mais a atenção é o fato de o jornal se colocar acima do Estatuto. A afirmação de que "em casos muito especiais, contudo, a omissão de nomes e imagens pode contribuir para que a sociedade se exima de sua responsabilidade sobre o problema, em prejuízo dos menores" não é clara. De que problema se fala? Como determinar que a preservação da identidade de um adolescente envolvido em um crime acarretaria prejuízo para ele? E, por fim, por qual razão o diretor de redação ou o editorchefe poderiam descumprir a lei?

Enfim, a única indicação ${ }^{12}$ explícita do manual de Zero Hora em relação à cobertura de temas ligados às crianças e aos adolescentes é ambígua, pois, em um primeiro momento, se preocupa em cumprir as determinações do ECA - mesmo que de forma inadequada -, mas depois defende seu descumprimento "em casos muito especiais", com argumentação pouco consistente.

Com base na discussão acima, percebemos que os manuais analisados, entendidos como discursos autorrepresentativos, falam das crianças e dos adolescentes para os repórteres que estão submetidos às suas diretrizes (e também ao público) apenas como seres protegidos pela lei. E é o receio da punição que rege a redação dos verbetes, ressaltando o descumprimento da legislação que a reportagem pode gerar, e não a preocupação com a criança como cidadã a quem o jornalismo deve servir. Ainda que haja incongruências não resolvidas na legislação em relação a esse balanço entre proteção e participação, é exemplar o fato de que nenhum dos jornais analisados incentiva a escuta de crianças e adolescentes em reportagens em que elas são protagonistas, por exemplo. Além disso, ao utilizar as crianças em exemplos textuais, os jornais reforçam a relação delas com infração ou risco, representando-as a partir de estereótipos dicotômicos - ser

\footnotetext{
${ }^{12}$ No Índice remissivo há os termos "menores" e "Estatuto da Criança e do Adolescente", que remetem a esse verbete.
} 


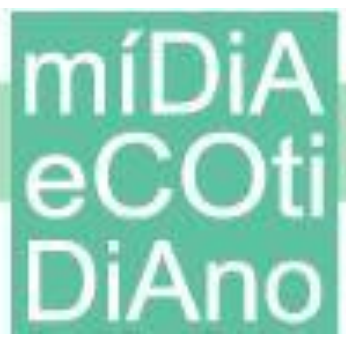

inocente, a ser amparado por toda a sociedade, ou marginalizado -, e dando margens para mostrá-las como incapazes de participar de decisões políticas. Esse tipo de tratamento dado à infância acaba por seguir outros modos de enxergar as crianças como atores sociais sem agência, como se vê em ambientes escolares e em esferas de decisão política (DORETTO; FURTADO, 2018), contribuindo para o recrudescimento dessa visão parcial sobre as crianças, e não para sua transformação. Vizeu (2008, p. 175), ao estudar diferentes manuais, já mostrava essa carência de atenção às práticas cidadãs, também voltadas aos adultos:

[as publicações] Devem ter em conta a "humanidade" de cada homem, de cada grupo que os tumultos da história transformam em "objetos" de informação. Trata-se de ver homens e mulheres como seres humanos, não como material informativo para alimentar o sistema jornalístico.

Apesar de já existir um avanço em relação à forma de tratamento das crianças e adolescentes na prática do jornalismo no Brasil, pela preocupação com certos aspectos do ECA, os jornais, em seus guias de cobertura e escrita, se esquecem das crianças nas suas múltiplas dimensões, como seres que atuam em diversos setores da sociedade e fazem parte da vida cotidiana dos bairros, das cidades. Além disso, a legislação não é citada no seu escopo de promoção da participação das crianças na mídia, como ocorre com os artigos da Convenção sobre os Direitos da Criança que garantem sua liberdade de expressão ou o seu direito a receber informações adequadas ao seu desenvolvimento cognitivo e à sua vivência.

\section{Considerações finais}

Existe uma preocupação crescente com o desinteresse das crianças e dos adolescentes em relação aos noticiários e à política, como se eles fossem responsáveis por isso. "No entanto, podemos virar esse argumento do avesso. A aparente rejeição dos jovens à política e ao jornalismo pode também ser entendida como um reflexo de seu sentimento de exclusão do campo da política e das formas dominantes de discurso público" (BUCKINGHAM, 2000, p. 249, grifo do autor). Por essa perspectiva, de acordo com Buckingham, eles não poderiam ser considerados apáticos ou irresponsáveis, mas destituídos. Caberia ao jornalismo repensar as formas como organiza seu discurso para 


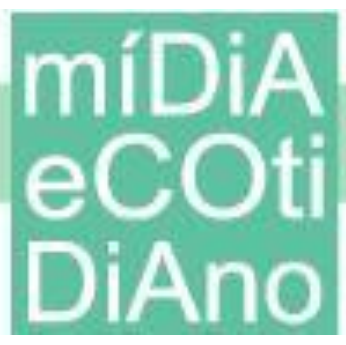

atrair e incluir as crianças e os adolescentes, potencializando-se como um meio significativo de educação política e de formação de cidadania.

Nesse sentido, Buckingham (2000, p. 263) propõe que se reflita sobre o que é considerado notícia hoje: "As notícias não podem mais ficar confinadas às palavras e aos atos dos poderosos ou aos discursos estreitos e elitistas que dominam atualmente a esfera pública e o debate político". Como o autor, defendemos que crianças e adolescentes devem ser considerados cidadãos e que cabe também ao jornalismo reforçar não apenas os direitos de proteção desse grupo, mas também suas garantias de participação na vida social, ainda que isso não esteja livre de incoerências e obstáculos. Sabemos, como já pontuamos, que a prática jornalística é complexa e não se limita ao que os manuais determinam ou ignoram. Também cabe ressaltar que não se pode generalizar e afirmar que o jornalismo como um todo no Brasil nunca contribui para o exercício da cidadania das crianças. Entretanto, infelizmente, não é essa a proposição que se encontra nas normas estabelecidas pelos jornais de maior circulação no Brasil como modos de tratar a infância e adolescência. Ou seja, a promoção da criança cidadã não faz parte das preocupações desses periódicos nas construções de seus discursos identitários, como veículos de mídia, perante a sociedade a que devem (e dizem) servir.

Consideramos que os achados aqui compartilhados sobre os manuais de redação de três dos principais jornais impressos brasileiros podem contribuir para a reflexão sobre a forma como o jornalismo vem representando as crianças e adolescentes. Quando

comparamos edições anteriores dos manuais com as mais recentes, é possível perceber que já existe um avanço em relação a essa temática, mas ainda há um grande caminho a ser percorrido. Destacamos que seria interessante ampliar essa análise para mais periódicos, com o objetivo de perceber possíveis diferenças regionais. Outro estudo a ser realizado envolveria manuais de outros veículos jornalísticos, além dos jornais, de forma a compreender como são as diretrizes para a cobertura.

Porém, como partimos do princípio de que a infância é uma construção social sempre em movimento e que o jornalismo também está em constante transformação, acreditamos ser inevitável que esse debate acabe se impondo e que as crianças e adolescentes passem cada vez mais a serem considerados em suas diferentes dimensões pelos jornalistas. Esse tem sido nosso esforço como pesquisadoras. 


\section{miDiA
DCOA
DAAnO}

\section{Referências}

ALBUQUERQUE, Afonso de; HOLZBACH, Ariane. Metamorfoses do contrato representativo: jornalismo, democracia e os manuais da redação da Folha de S. Paulo. Comunicação, Mídia e Consumo, v. 5, n. 14, p. 149-170, 2008.

BRASIL. Decreto ${ }^{\circ} 99.710$, de 21 de novembro de 1990. Promulga a Convenção sobre os Direitos da Criança. Diário Oficial da União, Brasília, 21 nov. 1990a.

BRASIL. Lei no 8.069, de 13 de julho de 1990. Dispõe sobre o Estatuto da Criança e do Adolescente e dá outras providências. Diário Oficial da União, Brasília, 16 jul. 1990b.

BREED, Warren. Controlo social na redacção. Uma análise funcional. In: TRAQUINA, N. (Org.). Jornalismo: questões, teorias e "estórias". Lisboa: Vegas, 1993, p. 152-166.

BUCKINGHAM, David. Crescer na era das mídias eletrônicas. São Paulo: Edições Loyola, 2000 .

CAPRINO, Mônica. Manual de redação: camisa-de-força ou regra necessária? Revista Imes, São Caetano do Sul, v. 4, n. 4, p. 49-59, jan./jun. 2002a.

CAPRINO, Mônica. Questão de estilo: o texto jornalístico e os manuais de redação. Comunicação \& Sociedade, ano 23, n. 37, p. 105-123, 2002 b.

FOLHA DE S. PAULO. Manual da Redação. 7. ed. São Paulo: Publifolha, 2001.

FOLHA DE S. PAULO. Manual da Redação. 21. ed. São Paulo: Publifolha, 2018.

DORETTO, Juliana; FURTADO, Thaís. A "invasão" das crianças no discurso jornalístico: a representação não desejada da infância. E-Compós, v. 21, n. 2, ID 1471, mai./ago. 2018.

DORETTO, Juliana; FURTADO, Thaís. O início é o fim: consumo cultural e o discurso sobre a infância no documentário "O começo da vida". In: XXVII ENCONTRO ANUAL DA COMPÓS, 2019, Porto Alegre. Anais... Brasília: Compós, 2019.

FURTADO, Thaís; DORETTO, Juliana. O "menino negro" da foto: a produção de sentidos nos comentários dos leitores do El País. Brazilian Journalism Research, v. 15, n. 1, p. 152-179, abr. 2019.

GRILLO, Sheila. Manuais de redação e estilo: gêneros do discurso, linguagem e objetividade na imprensa. The ESPecialist, v. 24, n. especial, p. 85-110, 2003.

LAGO, Claudia. Ensinamentos antropológicos: a possibilidade de apreensão do "Outro" no jornalismo. Brazilian Journalism Research, v. 11, n. 2, p. 172-187, 2014.

MARQUES DE MELO, José. Gilberto Freyre: o modernizador precoce da imprensa brasileira. In: MARQUES DE MELO, J. Imprensa brasileira: personagens que fizeram a história. São Paulo: Universidade Metodista/Imprensa Oficial de São Paulo, 2005.

O GLOBO. Manual de redação e estilo. 28. ed. São Paulo: Editora Globo, 2001. 
PONTE, Cristina. Crianças em notícia: a construção da infância pelo discurso jornalístico (1970-2000). Lisboa: ICS - Imprensa de Ciências sociais, 2005.

PREVEDELLO, Carine. Representações no jornalismo popular: a cidadania no discurso do Extra (RJ). (Dissertação de Mestrado em Comunicação) - Universidade Federal de Santa Maria, Santa Maria-RS, 2008.

REDE ANDI BRASIL. Estatuto da Criança e do Adolescente: um guia para jornalistas. 2. ed. Brasília: Rede Andi Brasil, 2011.

REGINATO, Gisele. As finalidades do jornalismo: o que dizem veículos, jornalistas e leitores. (Tese de Doutorado em Comunicação e Informação) - Universidade Federal do Rio Grande do Sul, Porto Alegre-RS, 2016.

ROSEMBERG, Fúlvia; MARIANO, Carmem Lúcia. A Convenção Internacional sobre os Direitos da Criança: debates e tensões. Cadernos de Pesquisa, v. 40, n. 141, set./dez. 2010.

VIZEU, Alfredo. Gilberto Freyre e os manuais de redação. Comunicação \& Sociedade, ano 29 , n. 50, p. 163-177, $2^{\circ}$ sem. 2008.

ZERO HORA. Manual de ética, redação e estilo. Porto Alegre: L\&PM, 1994.

ZERO HORA. Normas de Redação. Porto Alegre: [s.n.], 1974. 